\title{
Study on Adsorption Properties of Vanadium Catalysts for $\mathbf{N H}_{3}$
}

\author{
Zhilin Liu \\ Department of Engineering Mechanics \\ Agricultural and Animal Husbandry College of \\ Tibet University \\ Linzhi, China \\ Linlin0324ok@126.com
}

\author{
Jun Bai \\ Department of Energy and Power Engineering \\ Agricultural and Animal Husbandry College of \\ Tibet University \\ Linzhi, China
}

\begin{abstract}
This paper describes the preparation process of vanadium catalysts. The adsorption capacity of vanadium catalysts for $\mathrm{NH}_{3}$ (stable adsorption time, ammonia storage capacity, contact adsorption) were obtained from test method. The relationship between the catalyst adsorption capacity and space velocity, temperature, gas concentration was gotten through comparison and analysis of data.
\end{abstract}

Keywords-catalyst; adsorption; ammonia storage capacity; contact adsorption

\section{INTRODUCTION}

\section{A. Exhaust Emissions Harmful to Health and Environment}

The car ownership increased significantly with the rapid development of China's automobile industry in recent years. However, the problems of exhaust emissions to environmental pollution have become increasingly prominent, seriously threatens people's living environment. Automobile exhaust has become the No.1 pollution sources of city air pollution which displayed by city air quality monitoring results [1][2]. Nitrogen oxides (NOx) is the main gaseous pollutants in the exhaust, its harm is related to many aspects of ecology, infrastructure, health etc.. For example: NO will become toxic gas named " photo-chemical smog " in the sunshine, causing damage to eye, throat, lung and other organs, and may cause heart damage, seriously endanger human life.

\section{B. The Application of Vanadium Catalysts in Emission Control Technology}

In order to solve the serious problem of exhaust pollution, many automobile manufacturers and R\&D department have found a exhaust emission control technology which in line with China's national conditions--selective catalytic reduction (SCR) technology. This technology is favored because it could effectively overcome the effect of sulfur content in vehicle diesel oil. The concentration of $32.5 \%$ urea aqueous solution is the reducing agent of SCR technology, urea decomposition of $\mathrm{NH}_{3}$ under high temperature, then $\mathrm{NH}_{3}$ and NOx in the exhaust will become no pollution gas such as $\mathrm{N}_{2}$ and $\mathrm{H}_{2} \mathrm{O}$ through reaction in the presence of catalyst, the purpose of emission reduction is achieved.

As one of the core technology of SCR technology, catalysts' performance affects the final discharge of NOx directly. Car manufacturers make catalyst and diesel engine matching, install catalyst on the exhaust pipe line, testing whether meet the emission standard. However, many studies [3][4] on vanadium catalysts' reaction mechanism in reduction reaction found that the key question is the adsorption capacity of vanadium catalysts to $\mathrm{NH}_{3}$. Catalyst' efficiency can't reach the highest if the adsorption performance of vanadium catalysts is unknown, it will cause waste of resources. Therefore, how to effectively use the adsorptive capacity of the catalyst will become the key to SCR technology to reduce NOx emissions.

\section{The PREPARATION OF VANAdiUm CATAlyst}

The concept of catalyst was defined by IUPAC in 1981. Vanadium catalysts have become the most widely used and effective catalysts for SCR technology because they have many advantages such as high conversion efficiency, low cost, strong selectivity, stable quality, high antitoxic stability and etc... The major preparation methods of vanadium catalyst include blending, precipitation and dip-molding [5]. At present, dip-molding is the most widely used, its performance can be good because it makes active constituent -- $\mathrm{V}_{2} \mathrm{O}_{5}$ distribute on the surface of the carrier. In order to improve catalytic ability and heat-drug stability, the activating treatment to catalyst in high temperature water vapor after preparation. The steps of preparation for vanadium catalyst are as follows [6]:

Step 1: preparing catalyst solution

Weigh a certain amount of oxalic acid and ammonium metavanadate respectively and dissolve them into distilled water, put in some silicate material, $\mathrm{WO}_{3} / \mathrm{TiO}_{2}$ powder mixture and other trace elements, then stir them in mixer, measuring its $\mathrm{PH}$ value and particle diameter at set intervals until it meet requirements.

Step 2: Immersion of catalyst carrier

Dip the carrier (cordierite honeycomb ceramics) prepared in the catalyst solution which has been prepared in full immersion, take it out and air-dry, and then dry it at low temperature after put it into then oven, setting the temperature at $110^{\circ} \mathrm{C}$. Weighing it after cool it at room temperature. Repeat immersion, drying until it meets the amount of coverage demand. The mass fraction of $\mathrm{V}_{2} \mathrm{O}_{5}$ and $\mathrm{WO}_{3}$ should meet the requirement in the preparation of catalyst.

Step 3: Activation

Put the catalysts which meet requirements into temperature - control electric furnace, roasting it one hour 
at $450^{\circ} \mathrm{C}$, and then cooling it to nature temperature after take out. The ammonium salt in the catalyst will be metallic oxide, water vapor and $\mathrm{NH}_{3}$, the metallic oxide is needed. The chemical equations are as follows:

$$
\begin{gathered}
\mathrm{C}_{2} \mathrm{H}_{2} \mathrm{O}_{4} \cdot 2 \mathrm{H}_{2} \mathrm{O} \rightarrow \mathrm{CO}_{2}+\mathrm{H}_{2} \mathrm{O} \\
\mathrm{NH}_{4} \mathrm{VO}_{3} \rightarrow \mathrm{NH}_{3}+\mathrm{V}_{2} \mathrm{O}_{5}+\mathrm{H}_{2} \mathrm{O} \\
\left(\mathrm{NH}_{4}\right)_{5} \mathrm{H}_{6}\left[\mathrm{H}_{2}\left(\mathrm{WO}_{4}\right)_{6}\right] \cdot 6 \mathrm{H}_{2} \mathrm{O} \rightarrow \mathrm{NH}_{3}+\mathrm{WO}_{3}+\mathrm{H}_{2} \mathrm{O}
\end{gathered}
$$

The catalyst just to preparation need to be activated because it has weak activity and stability. Put it into electric oven, heating it 1 hour in steam at the temperature between $650^{\circ} \mathrm{C}$ and $680^{\circ} \mathrm{C}$, it will be $\mathrm{OK}$ after natural cooling to room temperature.

\section{The Adsorption Test of CAtalysts to $\mathrm{NH}_{3}$}

\section{A. Test Scheme}

The airspeed and temperature are two factors that influent the adsorption performance of catalyst. In addition, the concentration of $\mathrm{NH}_{3}$ of the exhaust will also affect the adsorption rate, and then affects the efficiency of catalytic reaction. In order to study the effect of space velocity, temperature and concentration on adsorption properties of catalysts, did tests according to ESC method, got that the range of exhaust airspeed is $34480 \sim 135400 \mathrm{~h}^{-1}$ (without considering idle condition), the range of exhaust temperature is $216 \sim 509^{\circ} \mathrm{C}$, the range of $\mathrm{NH}_{3}$ concentration required to completely eliminate NOx is $250 \sim 1383 \mathrm{ppm}$.

Based on the above, the test scheme is as follows:

Temperature points: $200^{\circ} \mathrm{C}, 300^{\circ} \mathrm{C}, 400^{\circ} \mathrm{C}, 500^{\circ} \mathrm{C}$;

Airspeed points: $30000 \mathrm{~h}^{-1}, 85000 \mathrm{~h}^{-1}, 140000 \mathrm{~h}^{-1}$;

Balance gas flow points: $0.833 \mathrm{~L} / \mathrm{min}, 2.36 \mathrm{~L} / \mathrm{min}$, 3.89L/min;

NH3 concentration points: 200ppm, 500ppm, 1000ppm, 1800ppm

The volume of test catalyst is $1.806 \times 10^{-6} \mathrm{~m}^{3}$, the balance gas is $\mathrm{N}_{2}$.

Test scheme has been determine, there are three factors temperature, airspeed and $\mathrm{NH}_{3}$ concentration. Therefore, if comprehensively study the adsorption capacity of catalyst in different temperature, airspeed and $\mathrm{NH}_{3}$ concentration, 48 experiments are needed (4 temperatures, 3 airspeeds; $4 \mathrm{NH}_{3}$ concentrations).

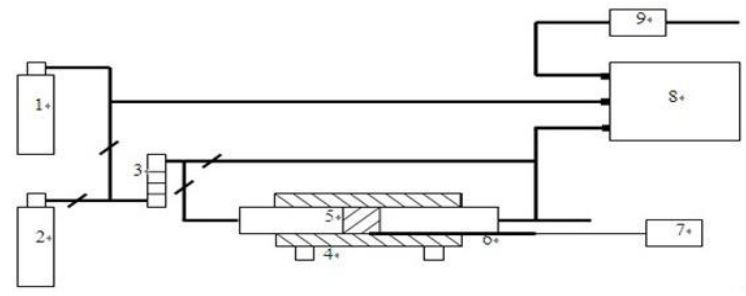

1- $\mathrm{N}_{2}$ 2-Sample gas $\left(\mathrm{NH}_{3}\right)$ 3-Flow meter 4-Heating furnace 5-Catalyst 6-Thermocouple 7-Temperature controller 8-Gas analyzer 9-Pump

Figure 1. The structure of installation

\section{B. Test installation}

The test device comprises the following gas analyzer, computer, the catalyst sample, heating furnace, temperature controller, flow meter, gas (tank) and switches, valves and piping and other components, the structure of installation as shown in figure 1 .

\section{THE ADSORPTION PROPERTIES ANALYSIS OF VANADIUM CATALYSTS TO $\mathrm{NH}_{3}$}

Catalysts' evaluating indicators include adsorption stability time (s), the ammonia storage capacity $\left(\mathrm{mol} / \mathrm{m}^{3}\right.$.), the adsorption rate $(\mathrm{mol} / \mathrm{h})$ and contact adsorption capacity $\left(\mathrm{mol} /\left(\mathrm{m}^{3} \cdot \mathrm{h}\right)\right)$. Adsorption stability time is a time interval that from the time point of open sample value $\left(T_{0}\right)$ to the time point of concentration began to stable $\left(\mathrm{T}_{1}\right)$. The ammonia storage capacity is $\mathrm{NH}_{3}$ amount the catalyst can store per volume, obtained the difference between calibration value and $\mathrm{NH}_{3}$ concentration of catalyst's outlet at each time point, did data fitting and time integration in the adsorption stable time quantum, and then the ammonia storage capacity of catalyst could be calculated according to sample gas flow. Contact adsorption is $\mathrm{NH}_{3}$ amount the catalyst can store in the contact time of catalyst and $\mathrm{NH}_{3}$.

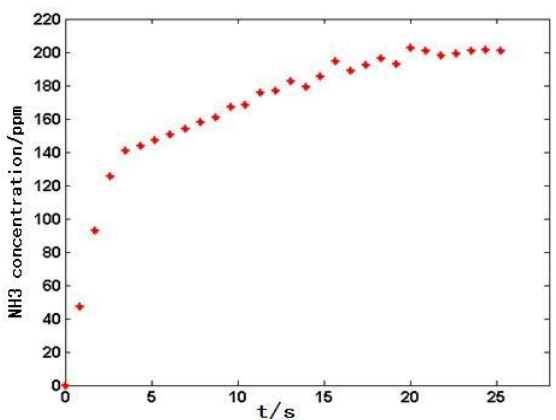

Figure 2. $\mathrm{NH}_{3}$ concentration changes at the outlet of catalytic

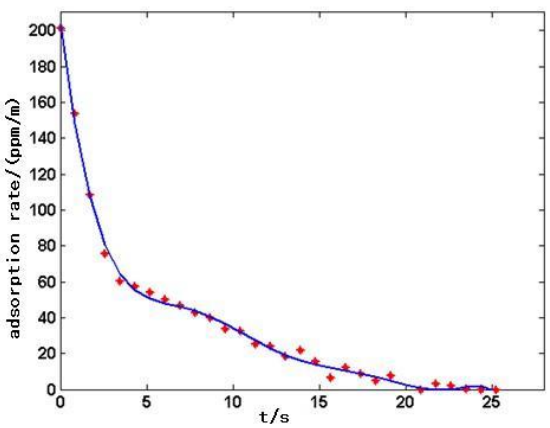

Figure 3. The absorption rate changes of catalyst to $\mathrm{NH}_{3}$

\section{A. The Adsorption Rate}

In the case of $200 \mathrm{ppm} \mathrm{NH}_{3} 、 30000 \mathrm{~h}^{-1} 、 200^{\circ} \mathrm{C}$, its calibration value is $201 \mathrm{ppm}$. The $\mathrm{NH}_{3}$ concentration change condition accompanied time measured by gas analyzer at the outlet of catalyst as shown in figure 2. Did the difference between calibration value of sample gas (201ppm) and $\mathrm{NH}_{3}$ concentration each time point at catalyst's outlet, did 6th data fitting, the change of adsorption rate in unit time of 
catalyst to $\mathrm{NH}_{3}$ as shown in figure 3, the fitting relationship is shown in formula (4).

$$
\begin{aligned}
y(x)= & -0.0014 x^{6}+0.0264 x^{5}-0.2357 x^{4}+0.2927 x^{3} \\
& +10.4101 x^{2}-73.074 x+201.478
\end{aligned}
$$

$\mathrm{x}$ - time $(\mathrm{t}), \mathrm{y}$ - the adsorption rate of catalyst to $\mathrm{NH}_{3}$.

There is a question need to explain that variable $\mathrm{y}$ is not strictly adsorption rate, but a visual representation adsorption rate of catalyst to $\mathrm{NH}_{3}$. The $\mathrm{NH}_{3}$ flow pass through catalyst in unit time is certain in the condition of sample gas flow and $\mathrm{NH}_{3}$ are certain. Therefore, the adsorption amount of catalyst to $\mathrm{NH}_{3}$ each unit time could be shown according to the difference between $\mathrm{NH}_{3}$ concentration at catalyst outlet and calibration value, the adsorption rate will be represented indirectly.

\section{B. Adsorption Stability Time}

Adsorption stability time is a time interval that from the time point of open sample value $\left(\mathrm{T}_{0}\right)$ to the time point of concentration began to stable $\left(\mathrm{T}_{1}\right)$.

TABLE I. ADSORPTION STABILITY TIME OF CATALYST TO $\mathrm{NH}_{3}$

\begin{tabular}{|c|c|c|c|c|c|}
\hline $\mathbf{N H}_{\mathbf{3}} \begin{array}{c}\text { concentration } \\
\text { /ppm }\end{array}$ & \multirow{2}{*}{ airspeed $/ \mathbf{h}^{-\mathbf{1}}$} & \multicolumn{4}{|c|}{ temperature/ ${ }^{\circ} \mathbf{C}$} \\
\cline { 2 - 6 } & 30000 & 200 & 300 & 400 & 500 \\
\hline \multirow{3}{*}{200} & 85000 & 19.14 & 24.36 & 22.62 & 20.88 \\
\cline { 2 - 6 } & 140000 & 12.18 & 11.31 & 15.66 & 14.79 \\
\hline \multirow{3}{*}{500} & 30000 & 20.88 & 19.14 & 18.27 & 9.57 \\
\cline { 2 - 6 } & 85000 & 15.66 & 13.92 & 12.18 & 11.31 \\
\cline { 2 - 6 } & 140000 & 9.57 & 8.70 & 7.83 & 6.96 \\
\hline \multirow{3}{*}{1000} & 30000 & 15.66 & 14.79 & 13.92 & 12.18 \\
\cline { 2 - 6 } & 85000 & 11.31 & 10.44 & 8.70 & 7.83 \\
\cline { 2 - 6 } & 140000 & 7.83 & 6.96 & 6.09 & 6.09 \\
\hline \multirow{3}{*}{1800} & 30000 & 9.57 & 8.70 & 7.83 & 6.96 \\
\cline { 2 - 6 } & 85000 & 7.83 & 6.96 & 6.09 & 5.22 \\
\cline { 2 - 6 } & 140000 & 5.22 & 5.22 & 4.35 & 4.35 \\
\hline
\end{tabular}

We could find that the relationship of adsorption stability time and airspeed, $\mathrm{NH}_{3}$ concentration, temperature is negative correlation, and the effect of the first two is relatively large.

\section{The Ammonia Storage Capacity}

Assume that adsorption stability time of adsorption process is $\mathrm{t}$ seconds, start time node is $\mathrm{t}_{0}=0$ second, end time node is $t_{1}=t$ seconds, the gas flow pass through catalyst is $\mathrm{Q}$ $\mathrm{L} / \mathrm{min}$, the volume of catalyst is $\mathrm{Vm}^{-3}$, did definite integration between $t_{0}$ and $t_{1}$, the ammonia storage capacity of catalyst is as follow:

$$
C=\int_{0}^{t_{1}} \frac{Q \times y(t) \times 10^{-6}}{60 \times 22.4 \times V} d t\left(\mathrm{~mol} / \mathrm{m}^{3}\right)
$$

From the table 2, we could found that the effect of temperature to ammonia storage capacity of catalyst is relatively large, the ammonia storage capacity of catalyst will be weaken while temperature going up. However, ammonia storage capacity is almost not affected by airspeed and sample gas concentration, at the same temperature the difference of capacity amount within $4 \%$, it is equal considering the error of experiment and calculation. Get the average value of 12 ammonia storage capacity at a certain temperature, consider this average value as the ammonia storage capacity at this temperature, so we can obtain the ammonia storage capacity of catalyst at $200^{\circ} \mathrm{C}, 300^{\circ} \mathrm{C}$, $400^{\circ} \mathrm{C}$ and $500^{\circ} \mathrm{C}$ as shown in table 3 , the change of ammonia storage capacity of catalyst in the range of $200^{\circ} \mathrm{C}$ to $500^{\circ} \mathrm{C}$ will be gotten as shown in figure 4 after did interpolation at intervals of $0.1^{\circ} \mathrm{C}$.

TABLE II. THE AMMONIA STORAGE CAPACITY OF CATALYST

\begin{tabular}{|c|c|c|c|c|c|}
\hline \multirow{2}{*}{$\begin{array}{c}\mathbf{N H}_{3} \\
\text { concentration/ppm }\end{array}$} & \multirow{2}{*}{ airspeed/ $\mathbf{h}^{\mathbf{1}}$} & \multicolumn{4}{|c|}{ temperature/ ${ }^{\circ} \mathbf{C}$} \\
\cline { 2 - 6 } & & 200 & 300 & 400 & 500 \\
\hline \multirow{3}{*}{200} & 30000 & 0.3789 & 0.3288 & 0.2426 & 0.1742 \\
\cline { 2 - 6 } & 85000 & 0.3679 & 0.3265 & 0.2501 & 0.1813 \\
\cline { 2 - 6 } & 140000 & 0.3806 & 0.3184 & 0.2390 & 0.1807 \\
\hline \multirow{3}{*}{500} & 30000 & 0.3753 & 0.3312 & 0.2376 & 0.1769 \\
\cline { 2 - 6 } & 85000 & 0.3820 & 0.3248 & 0.2515 & 0.1799 \\
\cline { 2 - 6 } & 140000 & 0.3797 & 0.3331 & 0.2453 & 0.1802 \\
\hline \multirow{3}{*}{1000} & 30000 & 0.3665 & 0.3192 & 0.2340 & 0.1691 \\
\cline { 2 - 6 } & 85000 & 0.3822 & 0.3227 & 0.2507 & 0.1768 \\
\cline { 2 - 6 } & 140000 & 0.3693 & 0.3431 & 0.2553 & 0.1701 \\
\hline \multirow{3}{*}{1800} & 30000 & 0.3850 & 0.3411 & 0.2475 & 0.1883 \\
\cline { 2 - 6 } & 85000 & 0.3925 & 0.3542 & 0.2623 & 0.1897 \\
\cline { 2 - 6 } & 140000 & 0.3906 & 0.3430 & 0.2413 & 0.1911 \\
\hline
\end{tabular}

TABLE III. THE AMMONIA StORAGE CAPACITY OF CATALYST AT SEVERAL TEMPERATURES

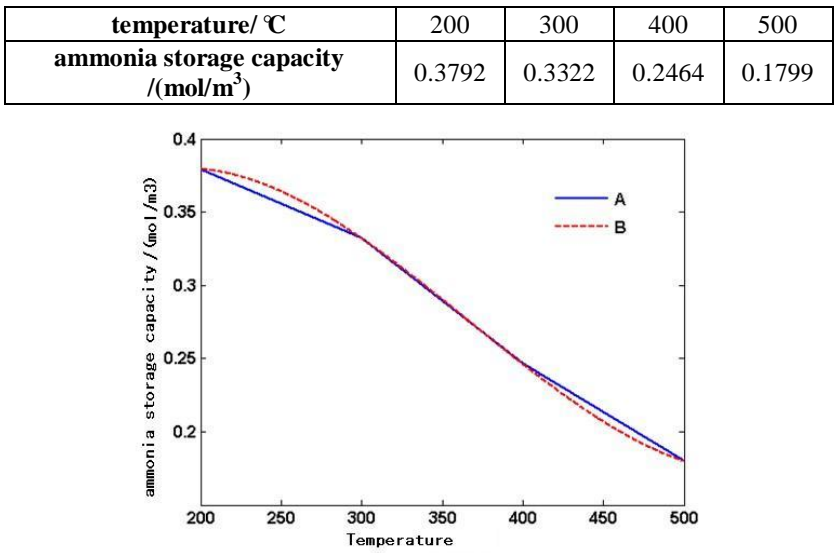

A-The original curve, B-The interpolation curve

Figure 4 . The ammonia storage capacity of catalyst

\section{Contact Adsorption Capacity}

There are not consider the contact time in the calculation of ammonia storage capacity, but contact time must be considered in the actual situation.

The contact time is the reciprocal of airspeed. The contact time is 0.12 seconds while airspeed is $30000 \mathrm{~h}-1$. The adsorption amount of catalyst to $\mathrm{NH}_{3}$ each unit volume could be obtained after integration between $0 \mathrm{~s}$ and $0.12 \mathrm{~s}$, this amount is contact adsorption of catalyst. The corresponding contact time of airspeed $30000 \mathrm{~h}^{-1}, 85000 \mathrm{~h}^{-1}$, $140000 \mathrm{~h}^{-1}$ are $0.12 \mathrm{~s}, 0.042 \mathrm{~s}, 0.027 \mathrm{~s}$ respectively.

Table 4 is the contact adsorption amount of catalyst to $\mathrm{NH}_{3}$, from table 4 we can find that contact adsorption amount is affected by sample gas concentration and almost 
not affected by temperature and airspeed, there is linear relationship between contact adsorption amount and sample gas concentration. Therefore, the key of contact adsorption amount is sample gas amount pass through catalyst in unit time. Effect of airspeed to contact adsorption amount could be ignored when sample gas concentration is certain.

TABLE IV. THE CONTACT ABSORPTION AMOUNT OF CATALYST TO $\mathrm{NH}_{3}$

\begin{tabular}{|c|c|c|c|c|c|}
\hline $\mathbf{N H}_{\mathbf{3}} \begin{array}{c}\text { concentration } \\
\text { /ppm }\end{array}$ & \multirow{2}{*}{ airspeed// $^{\mathbf{- 1}}$} & \multicolumn{4}{|c|}{ temperature $^{\circ} \mathbf{C}$} \\
\cline { 2 - 6 } & & 200 & 300 & 400 & 500 \\
\hline \multirow{3}{*}{200} & 30000 & 0.0082 & 0.0081 & 0.0076 & 0.0082 \\
\cline { 2 - 6 } & 85000 & 0.0079 & 0.0074 & 0.0081 & 0.0079 \\
\cline { 2 - 6 } & 140000 & 0.0081 & 0.0082 & 0.0079 & 0.0080 \\
\hline \multirow{3}{*}{500} & 30000 & 0.0201 & 0.0199 & 0.0195 & 0.0197 \\
\cline { 2 - 6 } & 85000 & 0.0202 & 0.0201 & 0.0200 & 0.0198 \\
\cline { 2 - 6 } & 140000 & 0.0197 & 0.0199 & 0.0201 & 0.0203 \\
\hline \multirow{3}{*}{1000} & 30000 & 0.0398 & 0.0403 & 0.0401 & 0.0399 \\
\cline { 2 - 6 } & 85000 & 0.0400 & 0.0401 & 0.0398 & 0.0399 \\
\cline { 2 - 6 } & 140000 & 0.0405 & 0.0402 & 0.0396 & 0.0394 \\
\hline \multirow{3}{*}{1800} & 30000 & 0.0724 & 0.0718 & 0.0721 & 0.0715 \\
\cline { 2 - 6 } & 85000 & 0.0728 & 0.0713 & 0.0725 & 0.0722 \\
\cline { 2 - 6 } & 140000 & 0.0719 & 0.0724 & 0.0721 & 0.0720 \\
\hline
\end{tabular}

TABLE V. THE CONTACT ABSORPTION AMOUNT OF CATALYST TO DIFFERENT CONCENTRATION SAMPLE GAS

\begin{tabular}{|c|c|c|c|c|}
\hline $\mathbf{N H}_{3}$ concentration/ppm & 200 & 300 & 400 & 500 \\
\hline $\begin{array}{c}\text { Contact adsorption } \\
/\left(\mathbf{~ m o l} / \mathbf{m}^{\mathbf{3}}\right)\end{array}$ & 0.3792 & 0.3322 & 0.2464 & 0.1799 \\
\hline
\end{tabular}

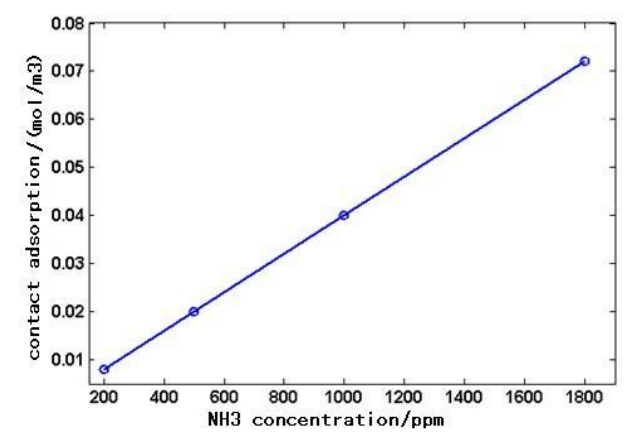

Figure 5. The contact absorption amount of catalyst to $\mathrm{NH}_{3}$

Get the average value of 12 contact adsorption amount at a certain concentration, consider this average value as the contact adsorption amount at this concentration, so we can obtain the contact adsorption amount of catalyst at 200ppm, 500ppm, 1000ppm and 1800ppm as shown in table 5, the contact adsorption amount of catalyst in different sample gas concentration will be gotten as shown in figure 5 after did the first-order fitting. The relation of contact adsorption amount and sample gas concentration is formula (6).

$$
y(x)=\frac{1}{25000} \cdot x
$$

$\mathrm{x}$-Sample gas concentration, $\mathrm{y}$-contact adsorption amount.

\section{CONCluSIONS}

1. It is feasible that the adsorption capacity of vanadium catalysts for $\mathrm{NH}_{3}$ is determined by test method. The adsorption capacity of vanadium catalysts (includes adsorption stable time, ammonia storage capacity and contact adsorption amount) was obtained by test method in this study.

2. The adsorption capacity of catalyst is affected by airspeed, temperature and sample gas concentration. The relationship of adsorption stability time and airspeed, $\mathrm{NH}_{3}$ concentration, temperature is negative correlation, but the effect of the first two is relatively large. The ammonia storage capacity of catalyst will be weaken while temperature going up. The relationship between contact adsorption capacity and sample gas concentration is proportion strictly.

\section{ACKNOWLEDGMENT}

This article is supported by "The project of comprehensive construction to rural energy (2013) ---The construction of ecological Demostration Village to the Development and Utilization of Tibet Energy".

\section{REFERENCES}

[1] Jun Qin, Lin Lv. "Study on the route of China IV heavy-duty diese engine technology" J. Engine information for vehicle, 2007, 5(4): pp. $4-9$

[2] Hong He, Duan Weng. "Overview of technology to diesel engine emission control" J. Environmental Science, 2007, 28(6): pp. 1169-1171

[3] N.-Y. Topsoe, J. A. Dumesic, H. Topsoe. Vanadia/Titania catalysts for selective catalytic reduction of nitric oxide by ammonia[J].Journal of catalysis, 1995(151):241-252.

[4] Giuseppe Salvatore Madia, Measures to enhance the NOx conversion in urea-SCR systems for automotive applications[D].University of Calabria(Italy), 2002

[5] Qin Xin. "Characterization of solid catalysts," M. Beijing: Science Press, 2004, pp: 54-56.

[6] Jianzhong Tao. "Study on technology of use SCR to reduce diesel nitrogen oxides,” D, Shandong University, 2008. pp: 3-4, 12, 24-25. 